Article

\title{
Comparative studies of leached Pt-Fe and Pt-Co catalysts for CO oxidation reactions
}

\author{
Hong Xu, Ke Ni, Xiaokun Li, Sheng Zhu, Guohong Fan * \\ School of Chemistry and Chemical Engineering, Anhui University of Technology, Maanshan 243002, Anhui, China
}

\section{A R T I C L E I N F O}

\section{Article history:}

Received 10 April 2017

Accepted 12 April 2017

Published 5 July 2017

\section{Keywords:}

$\mathrm{Pt}-\mathrm{Fe}$

Pt-Co

Acid leaching

CO oxidation

Surface oxide

\begin{abstract}
A B S T R A C T
Leached Pt-Fe and Pt-Co catalysts were prepared by acid leaching the reduced catalysts in acid solution. Oxidation treatments of leached catalysts produced the structure of metal oxides decorating the surface of nanoparticles. The fully oxidized $\mathrm{Fe}_{2} \mathrm{O}_{3}$ and $\mathrm{Co}_{3} \mathrm{O}_{4}$ species on Pt nanoparticle surfaces result in the low performance of the $\mathrm{CO}$ complete oxidation (COOX) reaction. In contrast, unsaturated $\mathrm{FeO}$ and $\mathrm{CoO}$ surface species can be formed during exposure to the $\mathrm{CO}$ preferential oxidation (CO-PROX) reaction with an excess of $\mathrm{H}_{2}$, leading to a high $\mathrm{O}_{2}$ activation ability and enhancing the CO-PROX activity. The $\mathrm{FeO}_{x}$ surface structures can be transformed between these two states by varying the reactive gas environments, exhibiting oscillating activity in these two reactions. Conversely, the $\mathrm{CoO}$ surface structure formed in the $\mathrm{H}_{2}$-rich atmosphere is stable when exposed to the COOX reaction and exhibits similar activity in these two reactions. It is hoped that this work may assist in understanding the important role of surface oxides in real reactions.
\end{abstract}

(C) 2017, Dalian Institute of Chemical Physics, Chinese Academy of Sciences. Published by Elsevier B.V. All rights reserved.

\section{Introduction}

It is generally recognized that the catalytic processes occur on the surface of nanoparticles (NPs) under reaction conditions. Therefore, the surface structure and composition of these materials have caused increasingly widespread interest, which has led to noteworthy modifications before and after reactions [1-3]. To obtain the active phases and catalytic mechanisms, it is necessary to study the structure-reactivity relationships during catalysis. Nevertheless, the enormous complexity of real powder catalysts makes them difficult to study from the aspect of atomistic understanding. Consequently, real supported catalysts may be simplified by model systems to a certain degree.

In recent years, inverse catalysts have been given much attention because of their excellent activity in many reactions, e.g., CO oxidation [4,5], the water-gas shift (WGS) [6-8], and $\mathrm{CO}_{2}$ hydrogenation $[9,10]$. Inverse catalysts are transition metal oxides (TMOs) supported on other metal surfaces [11]. Compared with conventional metal/oxide catalysts, inverse catalysts can increase the important role of metal oxides in the catalytic process. It has been shown that the special effects existing at the oxide-metal interface can affect the electronic and chemical properties of oxides, a process known as "strong oxide-metal interaction (SOMI)" [12]. For example, $\mathrm{TiO}_{2-x} / \mathrm{Au}(111)$ and $\mathrm{CeO}_{2-x} / \mathrm{Au}(111)$ inverse catalysts show superior activity in the WGS reaction [7]. Results reveal that reaction occurs at the metal-oxide interface, where the oxide nanoparticles dissociate water and nearby Au sites adsorb CO. The $\mathrm{CeO}_{x} / \mathrm{Cu}(111)$ inverse system is more active than $\mathrm{Cu} / \mathrm{CeO}_{2}$ (111) in the WGS reaction [8]. The high catalytic performance of $\mathrm{CeO}_{x} / \mathrm{Cu}(111)$ can be attributed to the special chemical properties of nano-sized ceria particles and the effects of the oxide-metal interface. Fu et al. [13-17] recently established an inverse catalytic system exhibiting higher catalytic

\footnotetext{
* Corresponding author. Tel: +86-555-2311807; E-mail: ghfan8@ahut.edu.cn

This work was supported by the National Natural Science Foundation of China (21403004, 21403003).

DOI: 10.1016/S1872-2067(17)62838-9 | http://www.sciencedirect.com/science/journal/18722067 | Chin. J. Catal., Vol. 38, No. 7, July 2017
} 
activity for low-temperature CO oxidation. This system consists of Pt surfaces decorated with TM (Fe, Co, Ni) oxides (TMO-on-Pt). An interface confinement effect between the TMOs and Pt has been suggested to stabilize coordinatively unsaturated (CUS) cations at oxide-Pt boundaries, which provides active sites for $\mathrm{O}_{2}$ activation. Other oxide/metal inverse systems have also been examined, including $\mathrm{SnO}_{x}[18,19], \mathrm{VO}_{x}$ $[20,21], \mathrm{CeO}_{x}[22]$, and $\mathrm{MgO}[23,24]$ overlayers on metal substrates.

SOMI is a common phenomenon in inverse oxide/metal catalysts [25]. It enables an important valence state transition of metal cations in the oxide component under reaction conditions. This transition leads to the formation of active phases (CUS cations), which are not stable in the bulk phase. Moreover, it introduces a unique interface to facilitate the catalytic reaction. So far, in oxide/metal inverse catalysts, most of the work performed has focused on model systems in which the substrate is a single crystal. The study of inverse systems in supported catalysts is more difficult than in the model systems because of their complicated structures. Hence, very little is known about this area with respect to powders.

This work introduces a new method to study supported inverse nanocatalysts for reaction performance. Acid leaching of supported Pt-Fe or Pt-Co nanoparticles can produce a Pt-rich surface and alloyed core nanostructure, leaving the surface TM and other spectators in acid solution $[16,17,26]$. Then, calcination of the leached NPs induces TM segregation to the surface and forms TM oxides. This structure is very similar to the TMO-on-Pt inverse system. CO complete oxidation (COOX) and CO preferential oxidation (CO-PROX) reactions were investigated using these leached inverse catalysts. Reaction results and characterization reveal that a phase transition of oxides occurred during the introduction of different reactive gases.

\section{Experimental}

\subsection{Preparation}

Pt-Fe/carbon black (CB) catalysts were prepared by a co-impregnation method using $\mathrm{H}_{2} \mathrm{PtCl}_{6} \cdot 6 \mathrm{H}_{2} \mathrm{O}$ and $\mathrm{Fe}\left(\mathrm{NO}_{3}\right)_{3} \cdot 9 \mathrm{H}_{2} \mathrm{O}$ as precursors $[16,17,26]$. The loadings of Pt and Fe were controlled at $4 \mathrm{wt} \%$ and $0.3 \mathrm{wt} \%$, respectively. The catalysts were dried overnight at $80{ }^{\circ} \mathrm{C}$ (denoted as fresh $\mathrm{Pt}-\mathrm{Fe} / \mathrm{CB}$ ) and then reduced in pure $\mathrm{H}_{2}$ at $450{ }^{\circ} \mathrm{C}$ for $2 \mathrm{~h}$ (denoted Pt-Fe/CB@450H). Then, $0.2 \mathrm{~g}$ of reduced sample was added to $200 \mathrm{~mL}$ of dilute $\mathrm{HNO}_{3}$ at room temperature (RT) for acid leaching treatment. After that, the solid samples were filtered and thoroughly washed with deionized water, and leached Pt-Fe/CB catalyst was obtained. The leached samples were further treated in air at various temperatures for $1 \mathrm{~h}$.

$\mathrm{Pt}-\mathrm{Co} / \mathrm{CB}$ catalysts were prepared in a similar process. The differences include the precursors $\left(\mathrm{H}_{2} \mathrm{PtCl}_{6} \cdot 6 \mathrm{H}_{2} \mathrm{O}\right.$ and $\left.\mathrm{Co}\left(\mathrm{NO}_{3}\right)_{2} \cdot 6 \mathrm{H}_{2} \mathrm{O}\right)$ and the reduction temperature of the fresh catalyst $\left(250{ }^{\circ} \mathrm{C}\right)$. The catalysts were denoted fresh Pt-Co/CB, Pt-Co/CB@250H, and leached Pt-Co/CB.

\subsection{Characterization}

All catalysts (50 mg), including fresh catalysts, reduced catalysts, and leached catalysts with various treatment temperatures, were washed in $50 \mathrm{~mL}$ of dilute acid solution $\left(\mathrm{HNO}_{3}, 1.7\right.$ mmol/L). The concentration of leached Fe (or Co) ions in the acid solutions was analyzed by inductively coupled plasma atomic emission spectrometry (ICP-AES) (Varian Vista-axial, Varian, Palo Alto, CA). X-ray diffraction (XRD) measurements were carried out using a Rigaku D/Max 2500 diffractometer with a $\mathrm{Cu} K_{\alpha}(\lambda=0.15406 \mathrm{~nm})$ radiation source. Transmission electron microscopy (TEM) characterizations were performed with a FEI Tecnai-G20 Spirit transmission electron microscope. X-ray photoelectron spectroscopy (XPS) spectra were obtained on Thermo Scientific ESCALAB 250Xi equipment with an Al $K_{\alpha}$ $\mathrm{X}$-ray source. The binding energies of all spectra were corrected using the reference of $\mathrm{C} 1 s$ at $284.6 \mathrm{eV}$.

\subsection{Catalytic activity}

CO oxidation reactions were performed in a fixed-bed microreactor with an online gas chromatograph to analyze the gas composition. The gas hourly space velocity (GHSV) was controlled at $30000 \mathrm{~mL} / \mathrm{g} \cdot \mathrm{h})$ if not specified. The COOX reaction gas consisted of $1 \% \mathrm{CO}, 20 \% \mathrm{O}_{2}$, and $79 \% \mathrm{Ar}$, and the CO-PROX reaction gas consisted of $1 \% \mathrm{CO}, 0.5 \% \mathrm{O}_{2}$, and $98.5 \% \mathrm{H}_{2}$. Before the reaction, catalysts were treated in flowing air at set temperatures for $1 \mathrm{~h}$. The catalytic performance was investigated from RT to $200^{\circ} \mathrm{C}$ with a heating rate of $1^{\circ} \mathrm{C} / \mathrm{min}$.

\section{Results and discussion}

\subsection{Characterization of Pt-Fe and Pt-Co catalysts}

An inward diffusion of 3d-TM atoms toward bulk regions and the surface segregation of Pt has often been observed when reducing Pt-TM catalysts at elevated temperatures [27-31]. The ratio of $3 \mathrm{~d}-\mathrm{TM}$ atoms located on the surface and in the core of NPs can be modulated by varying the temperature of reduction treatment $[16,17]$. 3d-TM atoms at particle surfaces can be dissolved in acid solutions, while those encapsulated by the Pt skin surface structure are unaffected $[16,17,26]$. Fig. 1 shows the XRD patterns of $\mathrm{Pt}-\mathrm{Fe} / \mathrm{CB}$ and $\mathrm{Pt}-\mathrm{Co} / \mathrm{CB}$ after various treatments. In Fig. 1(a), the characteristic peak for the face-centered cubic (FCC) Pt(111) of the Pt-Fe/CB@450H catalyst appears at $40.0^{\circ}$, higher than that of pure $\operatorname{Pt}\left(2 \theta=39.8^{\circ}\right)$. This indicates that significant inward diffusion of Fe into the $\mathrm{Pt}$ lattice occurs during the reduction at high temperatures, consistent with the above viewpoints. The pattern of the leached $\mathrm{Pt}-\mathrm{Fe} / \mathrm{CB}$ sample exhibits a similar diffraction peak position at $40.0^{\circ}$. Thus, only surface $\mathrm{Fe}$ is removed during acid leaching, and the inner structure of particles is not affected. Leached $\mathrm{Pt}-\mathrm{Fe} / \mathrm{CB}$ samples oxidized at 150,250 , and $350^{\circ} \mathrm{C}$ show similar patterns to the leached catalyst, with the diffraction peak located at $40.0^{\circ}$. A similar process occurred for the Pt-Co/CB with various treatments (Fig. 1(b)). The peak position of Pt-Co/CB@250H is observed at $40.0^{\circ}$, while the position does not change with acid-leaching treatment. The diffraction peaks of leached Pt-Co/CB samples with oxidation at 150, 250, and 

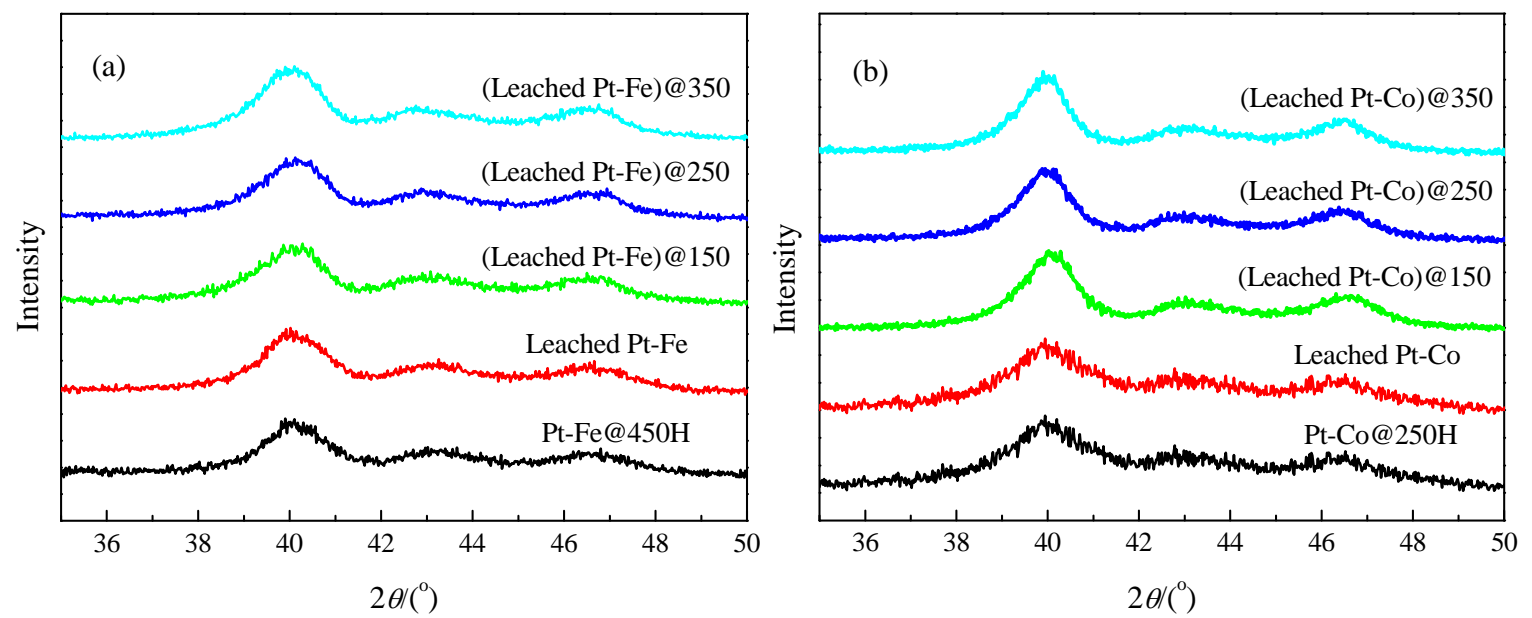

Fig. 1. XRD patterns of Pt-Fe/CB (a) and Pt-Co/CB (b) with various treatments.

$350{ }^{\circ} \mathrm{C}$ are observed at $40.0^{\circ}, 40.0^{\circ}$, and $39.9^{\circ}$, respectively. As shown for a series of Pt-based catalysts by $\mathrm{Mu}$ et al. [32], after oxidation in $\mathrm{O}_{2}$ at high temperatures, inner $3 \mathrm{~d}$-TM will diffuse outward and form TM oxides on the surface of NPs. A similar conclusion may be derived for our leached catalysts with oxidation treatment. The diffraction peak positions of leached catalysts with various oxidation temperatures remain almost the same because of the very small amount of 3d-TM. The outward diffusion of Fe or Co to the particle surface can be confirmed by the next measurements.

It has been reported that 3d-TM located on the surface of $\mathrm{Pt}$ nanoparticles can be dissolved in a suitable acid solution by acid leaching of Pt-based catalysts, while the inner structure will be unaffected because of the Pt-skin protection [17,26,33]. Therefore, the distribution of 3d-TM at the nanoparticle surface or inside can be measured. The remaining 3d-TM ions in the solution can be measured with inductively coupled plasma atomic emission spectrometry (ICP-AES) measurements. Hence, acid leaching combined with ICP measurements can be used as an effective method to study 3d-TM distribution at nanoparticle surfaces and in nanoparticle cores. In addition, the fresh Pt-based samples were investigated with acid leaching and ICP measurement. The percentage of the washed ions from these fresh samples is set as 100\%. Fig. 2 displays Fe and Co ion concentrations leached from $\mathrm{Pt}-\mathrm{Fe} / \mathrm{CB}$ and $\mathrm{Pt}-\mathrm{Co} / \mathrm{CB}$ catalysts with various treatments. A total of $36 \%$ Fe can be washed in

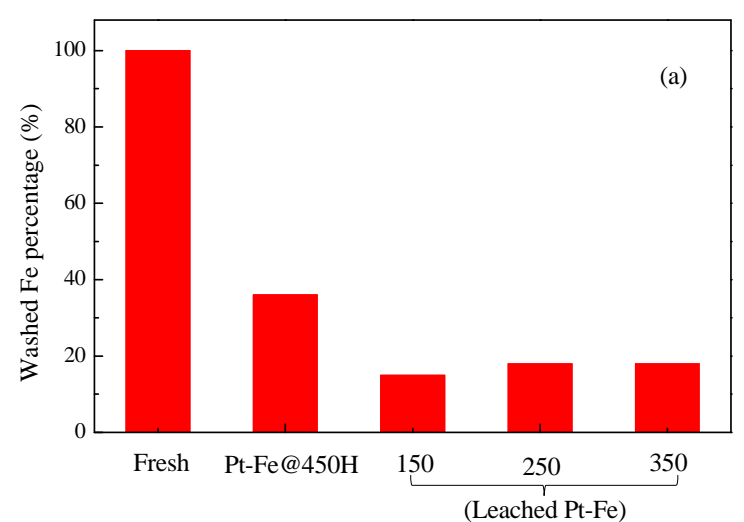

Pt-Fe/CB@450H, indicating most Fe atoms ( 64\%) exist in the form of a Pt-Fe alloyed structure in the particle core. The Fe percentages of leached Pt-Fe/CB with oxidation at 150, 250, and $350{ }^{\circ} \mathrm{C}$ are $15 \%, 18 \%$, and $18 \%$, respectively. These results are consistent with the XRD data, proving that the $\mathrm{Fe}$ atoms diffused from the particle core to the surface in leached Pt-Fe with elevated oxidation temperature. Similar results were observed in the Pt-Co system. The washed Co percentage is $60 \%$ in the Pt-Co/CB@250H, with values of $6 \%, 11 \%$, and $15 \%$ for leached Pt-Co with oxidation at 150,250 , and $350{ }^{\circ} \mathrm{C}$, respectively. Meanwhile, the sum of washed Fe or Co percentage in reduced samples and leached samples with oxidation (e.g. 350 ${ }^{\circ} \mathrm{C}$ ) is far less than $100 \%$. This indicates that oxidation treatment cannot drive all the inner alloyed Fe or Co atoms to the particle surface, leaving a portion in the particle core.

The nanostructures and size distributions of the Pt-Fe/CB and Pt-Co/CB catalysts were characterized by TEM, as shown in Fig. 3. The NPs in all samples have a narrow distribution in the size range of 1-3 nm. Representative high-resolution TEM (HRTEM) images reveal that NPs over Pt-Fe and Pt-Co samples have the same FCC Pt lattice, with a Pt(111) lattice fringe of $0.23 \mathrm{~nm}$. This is because the bulks of alloyed particles are dominated by Pt and low amounts of Fe or Co have little effect on the Pt lattice during the reduction process, as depicted in XRD and ICP measurements. On the other hand, this result suggests that the surface Fe or Co atoms have been removed

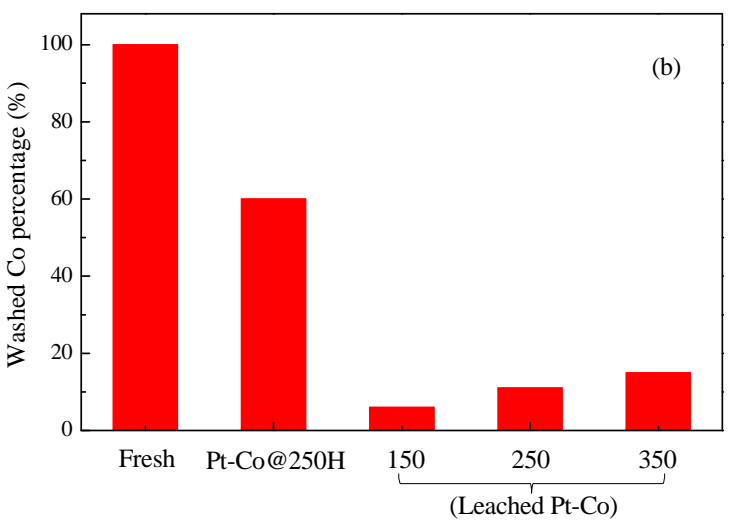

Fig. 2. Fe and Co ion concentrations leached from Pt-Fe/CB (a) and Pt-Co/CB (b) catalysts with various treatments. 

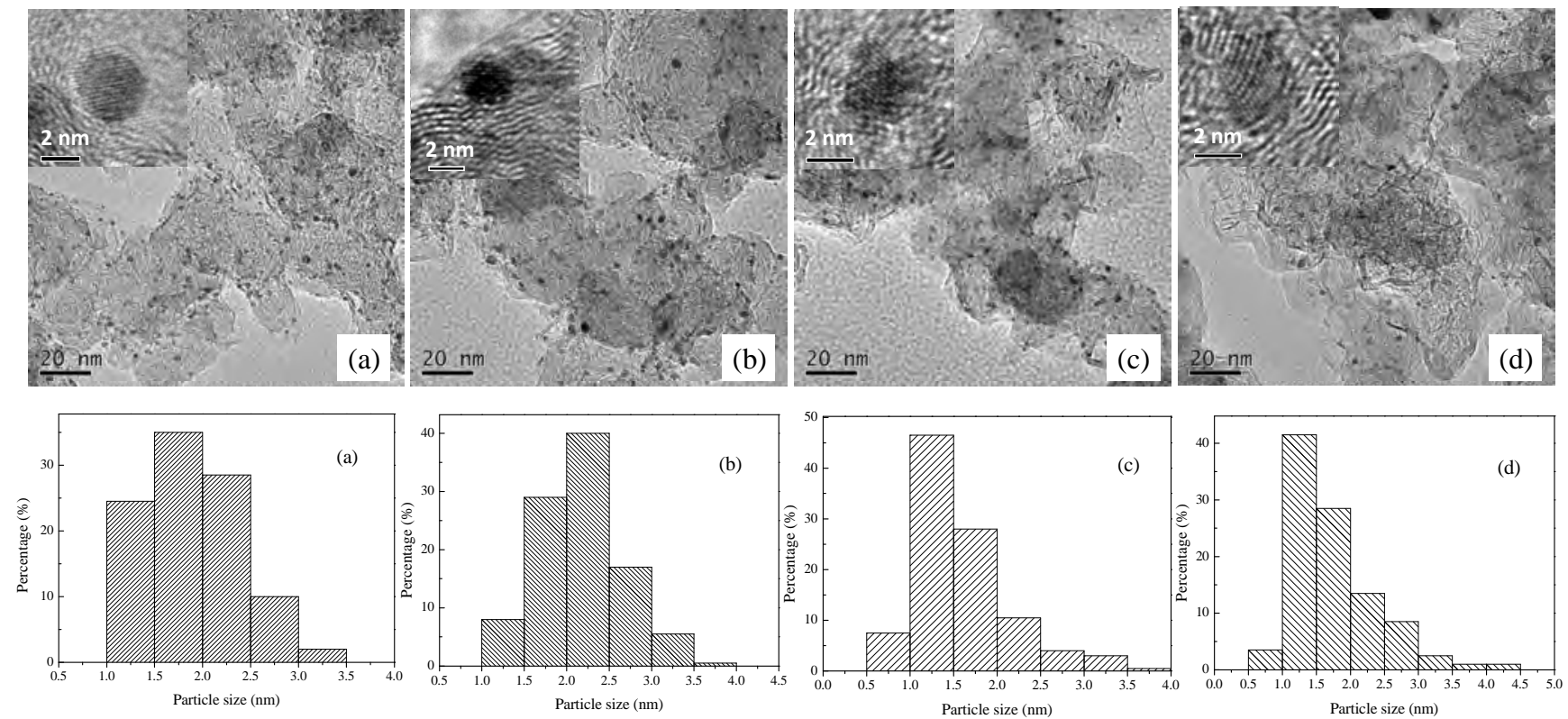

Fig. 3. TEM images (insets: HRTEM images) and particle size distributions of typical catalysts: (a) Pt-Fe/CB@450H; (b) Leached Pt-Fe/CB oxidized at $250{ }^{\circ} \mathrm{C}$; (c) Pt-Co/CB@250H; (d) Leached Pt-Co/CB oxidized at $250^{\circ} \mathrm{C}$

after acid leaching, leaving the inner structure unchanged.

Catalysts with various treatments were further investigated by XPS measurements. For comparison, the Fe/CB and Co/CB oxidized in air at $250{ }^{\circ} \mathrm{C}$ were tested. Fig. 4(a) shows the $\mathrm{Fe}$ $2 p_{3 / 2}$ peak of $\mathrm{Fe} / \mathrm{CB}$ oxidized at $250{ }^{\circ} \mathrm{C}$ located at $711.3 \mathrm{eV}$, which corresponds to $\mathrm{Fe}_{2} \mathrm{O}_{3}[34,35]$. The leached Pt-Fe catalyst shows a weak peak at $711.3 \mathrm{eV}$; in addition, metallic Fe located at $708.4 \mathrm{eV}$ can be clearly seen. This indicates that most of the surface $\mathrm{Fe}$ is washed in the acid-leaching process. Oxidation of leached Pt-Fe at $250^{\circ} \mathrm{C}$ drives alloyed metallic Fe to the surface, which oxidizes to $\mathrm{Fe}_{2} \mathrm{O}_{3}$, so that the metallic $\mathrm{Fe}(708.4 \mathrm{eV})$ signal becomes very weak. A similar situation exists in the Pt-Co system, as shown in Fig. 4(b). The Co $2 p_{3 / 2}$ binding energy (BE) of $\mathrm{Co} / \mathrm{CB}$ with $250{ }^{\circ} \mathrm{C}$ oxidation treatment is located at 780.5 $\mathrm{eV}$, with a weak satellite peak, which can be attributed to $\mathrm{Co}_{3} \mathrm{O}_{4}$.
After surface Co was washed in acid-leaching treatment, the catalyst shows a strong Co $2 p_{3 / 2}$ peak at $778.8 \mathrm{eV}$, corresponding to the alloyed metallic Co in the bulk. Oxidation of the leached sample at $250{ }^{\circ} \mathrm{C}$ in air leads part of the alloyed Co to diffuse to the particle surface, forming Co oxides $(780.5 \mathrm{eV})$ and strengthening the Co signal intensity. The typical difference between $\mathrm{Co}_{3} \mathrm{O}_{4}$ and $\mathrm{CoO}$ is that the latter has a strong shake-up satellite peak approximately 4.5-5 eV higher than its main peak and a spin-orbit coupling of approximately $15.5 \mathrm{eV}$ in the XPS spectra. Another distinguishing feature may be observed: the main peaks of Co $2 p$ in $\mathrm{CoO}$ upshift by approximately $1 \mathrm{eV}$ with respect to $\mathrm{Co}_{3} \mathrm{O}_{4}$, especially in Pt-Co systems [17,36-38]. Therefore, although the Co peak (Fig. 4(b)) with a strong satellite peak shows that the $\mathrm{Co}$ oxides may be $\mathrm{CoO}, \mathrm{Co}_{3} \mathrm{O}_{4}$ with a weak satellite peak cannot be eliminated and may be the pre-
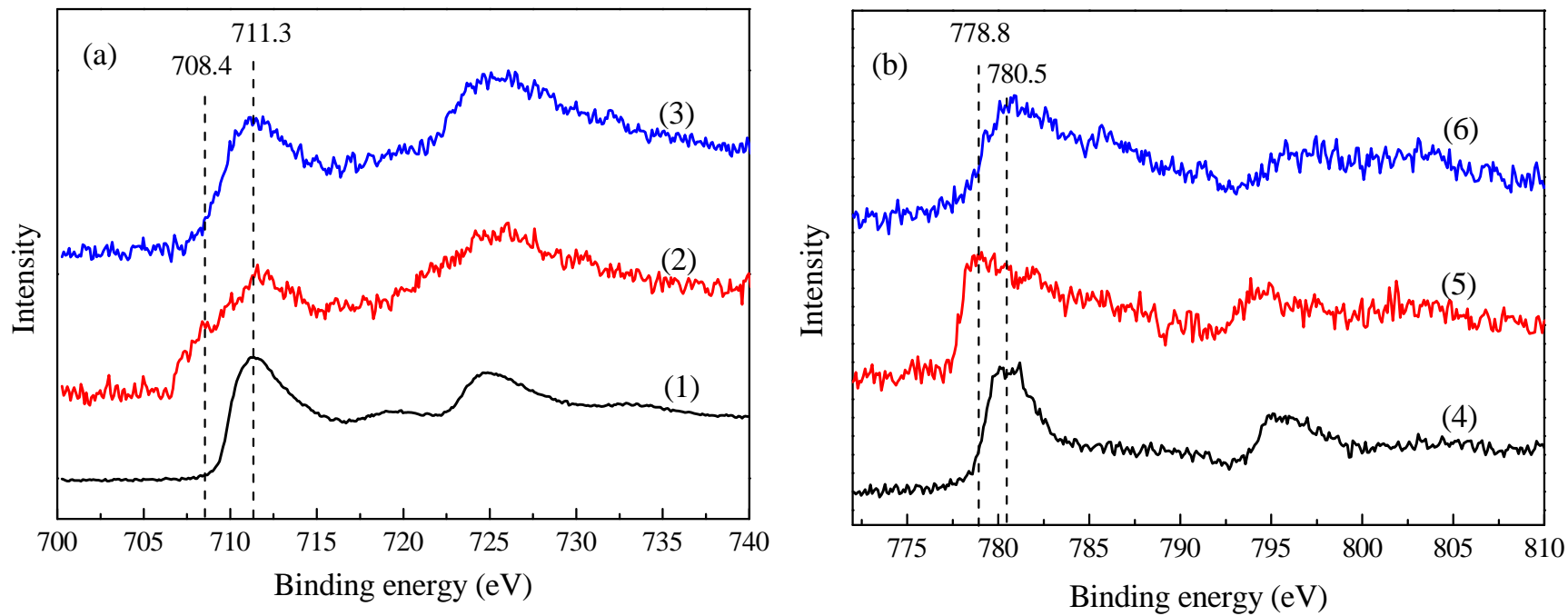

Fig. 4. Fe $2 p$ (a) and Co $2 p$ (b) XPS spectra of different samples. (1) Fe/CB oxidized at $250^{\circ} \mathrm{C}$, (2) leached Pt-Fe/CB, (3) leached Pt-Fe/CB oxidized at $250{ }^{\circ} \mathrm{C}$, (4) Co/CB oxidized at $250^{\circ} \mathrm{C}$, (5) leached Pt-Co/CB, (6) leached Pt-Co/CB oxidized at $250^{\circ} \mathrm{C}$. 
dominant oxide species in this oxidized Pt-Co sample [39,40]. In addition, the atomic ratio of Fe to Pt calculated from XPS increased from 0.25 to 0.33 from leached Pt-Fe/CB (Fig. 4(2)) to that oxidized at $250{ }^{\circ} \mathrm{C}$ (Fig. 4(3)). The increased tendency was also observed in the Pt-Co system, in which the Co/Pt atomic ratio was 0.16 over leached Pt-Co/CB (Fig. 4(5)) and increased to 0.26 after oxidation at $250{ }^{\circ} \mathrm{C}$ (Fig. 4(6)). These results further confirm the outward diffusion of Fe or Co from the cores of leached NPs to the surface with air treatment.

\subsection{Catalytic performance of leached Pt-Fe and Pt-Co catalysts}

Fig. 5 displays the CO conversion in COOX (a) and CO-PROX (b) reactions for leached Pt-Fe catalyst oxidized in air at 150, 250 , and $350{ }^{\circ} \mathrm{C}$. For the leached Pt-Fe catalyst oxidized at 150 ${ }^{\circ} \mathrm{C}$ and $250{ }^{\circ} \mathrm{C}$, the $\mathrm{CO}$ conversions are less than $10 \%$ at RT and the temperatures of $\mathrm{CO}$ complete conversion are approximately $160{ }^{\circ} \mathrm{C}$, similar values to those of pure Pt. When the oxidizing temperature increased to $350{ }^{\circ} \mathrm{C}$, the activity increased slightly, with $30 \%$ CO conversion at RT and $100 \%$ CO conversion at 160 ${ }^{\circ} \mathrm{C}$. On the other hand, the activity of the CO-PROX reaction is different with increasing oxidation temperature. For the leached Pt-Fe catalyst oxidized at $150{ }^{\circ} \mathrm{C}$, the $\mathrm{CO}$ conversion was only $40 \%$ at RT, reached a maximum of $80 \%$ at $80{ }^{\circ} \mathrm{C}$, and then decreased slightly as the temperature was increased further. When the oxidizing temperature increased to $250{ }^{\circ} \mathrm{C}$ and $350{ }^{\circ} \mathrm{C}$, the CO conversion reached to above $95 \%$ at RT, equivalent to the CO-PROX activity over Pt-Fe/CB catalyst with the same Pt content [16]. Real supported catalysts and surface science study have shown that a stable $\mathrm{FeO}_{1-x}$ structure confined at the Pt surface plays an important role in enhancing the activity of the CO-PROX reaction [41], while the fully oxidized $\mathrm{FeO}_{2-x}$ structure forms in an $\mathrm{O}_{2}$-rich atmosphere and exhibits low activity for the COOX reaction. In addition, the reciprocal transformation between $\mathrm{FeO}_{1-x}$ and $\mathrm{FeO}_{2-x}$ can be realized by switching the CO-PROX and COOX reaction atmospheres, resulting in oscillation in the catalytic performance. Consequently, after oxidizing the leached Pt-Fe/CB catalysts, the surface fully oxidized $\mathrm{Fe}_{2} \mathrm{O}_{3}$ displays low reactivity in the COOX atmosphere (Fig. 5(a)). When exposed to the $\mathrm{H}_{2}$-rich CO-PROX atmosphere, the surface $\mathrm{Fe}_{2} \mathrm{O}_{3}$ will be reduced to the highly active $\mathrm{FeO}$ structure for $\mathrm{O}_{2}$ dissociation because of the hydrogen spilling over effect [42,43], resulting in high CO conversion (Fig. 5(b)). To illustrate the important role of surface oxides in reaction, the performance of leached Pt-Fe/CB without air treatment were tested in both reaction gases, also shown in Fig. 5 (denoted non-treatment). The temperature of $100 \%$ CO conversion in the COOX reaction was approximately $110{ }^{\circ} \mathrm{C}$. For the CO-PROX reaction, the leached Pt-Fe/CB catalyst exhibited $35 \%$ CO conversion at RT and nearly $80 \%$ CO conversion at $110^{\circ} \mathrm{C}$. As the leached Pt-Fe/CB sample forms the structure of the Pt-skin combined with the Pt-Fe alloyed core, the reactivities of COOX and CO-PROX over leached Pt-Fe/CB are similar to those of the alloyed Pt-Fe catalyst [16,44].

Similarly, we investigated the CO conversion in COOX and CO-PROX reactions for leached Pt-Co catalysts oxidized in air at 150,250 , and $350{ }^{\circ} \mathrm{C}$. The reactivity of both reactions over leached $\mathrm{Pt}-\mathrm{Co} / \mathrm{CB}$ without oxidation treatment was also measured. The corresponding results are shown in Fig. 6. For the COOX reaction, the leached $\mathrm{Pt}-\mathrm{Co} / \mathrm{CB}$ with $150{ }^{\circ} \mathrm{C}$ oxidation showed similar reactivity to the Pt catalyst, as well as that without oxidation treatment. When the oxidation temperature increased to $250{ }^{\circ} \mathrm{C}$ and $350{ }^{\circ} \mathrm{C}$, the reactivity was slightly enhanced, with complete $\mathrm{CO}$ conversion at $110{ }^{\circ} \mathrm{C}$. In the CO-PROX reaction, leached Pt-Co catalysts with $250^{\circ} \mathrm{C}$ and 350 ${ }^{\circ} \mathrm{C}$ oxidation treatments showed better activity than that without oxidation and with $150{ }^{\circ} \mathrm{C}$ oxidation treatment. The CO conversion at RT was nearly $70 \%$, and $100 \%$ CO conversion was observed at $80{ }^{\circ} \mathrm{C}$ over leached $\mathrm{Pt}$-Co/CB oxidized at 250 ${ }^{\circ} \mathrm{C}$, only slightly lower than PROX activity over Pt-Co/CB@250H [17] and Pt-Co/CNT [38] with the same Pt loading, but higher than that over Pt-Co supported on other supports [38]. Zheng et al. [45] studied the oxidation states of 4-nm Co and CoPt bimetallic nanoparticles in the presence of $\mathrm{H}_{2}$ and $\mathrm{O}_{2}$ and found that Co oxide is much easier to reduce when alloying with $\mathrm{Pt}$ at a rather low temperature $\left(38^{\circ} \mathrm{C}\right)$. Therefore, surface $\mathrm{Co}_{3} \mathrm{O}_{4}$ species may be reduced to more highly active $\mathrm{CoO}$ after introducing CO-PROX gas $\left(\mathrm{H}_{2}\right.$-rich) because of the hydrogen spill over effect. These results demonstrate that $\mathrm{Co}_{3} \mathrm{O}_{4}$ is the main existing form, with a small amount of $\mathrm{CoO}$ present after oxida-
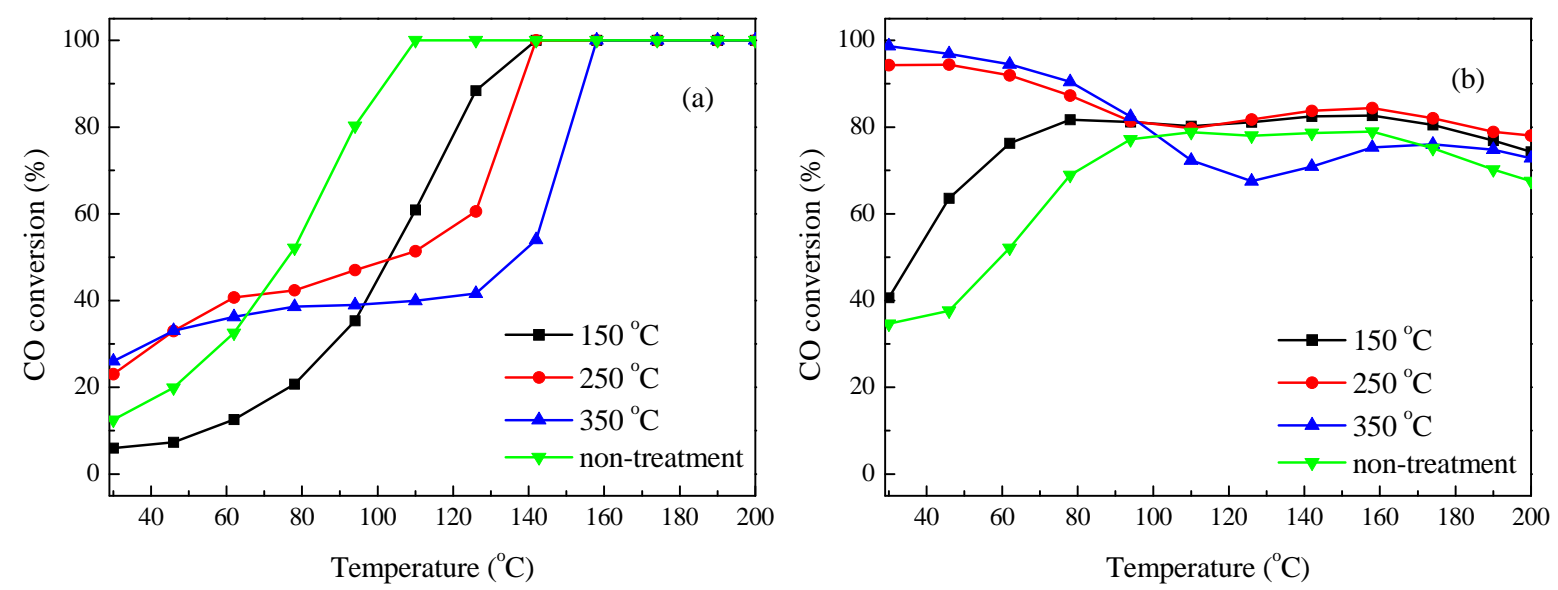

Fig. 5. CO conversion in COOX (a) and CO-PROX (b) reactions over leached Pt-Fe catalyst with non-treatment and that oxidized in air at 150, 250, and $350{ }^{\circ} \mathrm{C}$. 

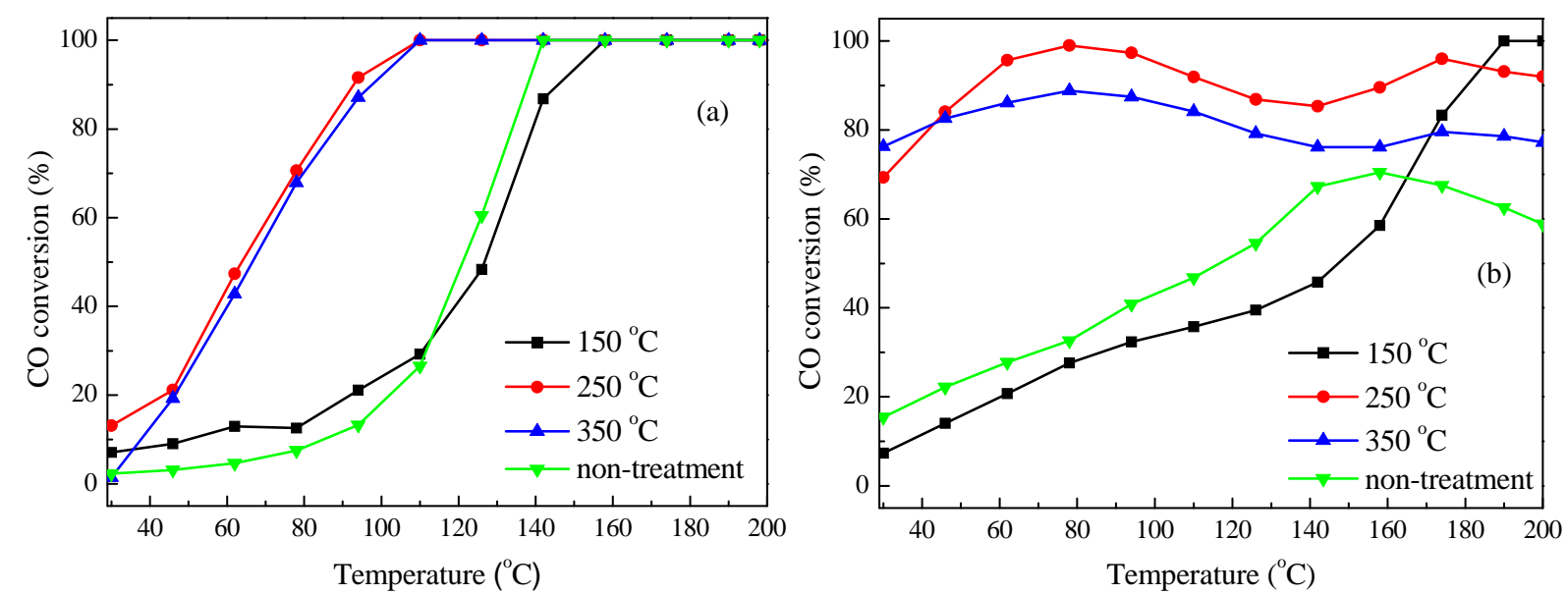

Fig. 6. CO conversion in COOX (a) and CO-PROX (b) reactions for leached Pt-Co catalyst with non-treatment and that oxidized in air at 150, 250, and $350^{\circ} \mathrm{C}$.

tion treatment of leached Pt-Co/CB, which induces a slight improvement in catalytic properties. Similar to the leached $\mathrm{Pt}-\mathrm{Fe} / \mathrm{CB}$, the surface $\mathrm{Co}_{3} \mathrm{O}_{4}$ phases will be reduced to $\mathrm{CoO}$ because of hydrogen spill over in the CO-PROX gas atmosphere, which improves the property of $\mathrm{O}_{2}$ dissociation and exhibits enhanced CO conversion.

From the characterization and reaction performance, it can be clearly seen that the reactivity of COOX and CO-PROX reactions over leached catalysts is largely influenced by the surface oxides. The above conclusions can be verified by cycling experiments with the COOX and CO-PROX changed several times, as depicted in Fig. 7 and Fig. 8. Fig. 7 displays the activity of leached Pt-Fe catalyst oxidized at $250{ }^{\circ} \mathrm{C}$ in the cycling experiments. All data were collected at $30{ }^{\circ} \mathrm{C}$. The CO conversion in COOX was $45 \%$ at first, decreasing to $30 \%$ after $1 \mathrm{~h}$ (Fig. 7(a)). When switching to the CO-PROX reaction, the CO conversion suddenly increased to $90 \%$ (Fig. 7(b)). This suggests that surface $\mathrm{Fe}_{2} \mathrm{O}_{3}$ on the Pt nanoparticles were converted to highly active $\mathrm{FeO}$ nanostructures under the $\mathrm{H}_{2}$-rich atmosphere, which could be stable because of the confinement effect of the $\mathrm{Pt}$ surface and $\mathrm{H}_{2}$-rich gas. When the reactive gas was changed back to COOX (Fig. 7(c)), the FeO structure formed in CO-PROX re-oxidized to low-activity $\mathrm{Fe}_{2} \mathrm{O}_{3}$ because of the $20 \% \mathrm{O}_{2}$, and a sharply decreased activity was observed, with only 15\% CO conversion. Then, switching to $\mathrm{H}_{2}$-rich PROX gas again (Fig. 7(d)), the leached Pt-Fe catalyst presents much higher CO conversion because highly active $\mathrm{FeO}$ was formed again. The next cycle exhibited similar activity as the reactive gas changes (Fig. 7(e) and (f)).

For the leached Pt-Co/CB catalyst oxidized at $250^{\circ} \mathrm{C}$ (Fig. 8), the CO conversion for the COOX reaction is approximately $30 \%$ (Fig. 8(a)), as much of the surface $\mathrm{Co}_{3} \mathrm{O}_{4}$ species present lower activity, although a small quantity of $\mathrm{CoO}$ also exists. When the reactive gas was changed to the CO-PROX reaction (Fig. 8(b)), the catalyst showed remarkably increased activity, with $70 \%$ CO conversion at first, but it later deactivated to $48 \%$ CO conversion after $1 \mathrm{~h}$. This may be explained by the substantial amount of $\mathrm{CoO}$ nanostructures formed on the surface of NPs because of the hydrogen spill over effect from Pt to the neighboring $\mathrm{Co}_{3} \mathrm{O}_{4}$. After exposure to the $\mathrm{COOX}$ gas atmosphere again at $30{ }^{\circ} \mathrm{C}$ (Fig. 8(c)), the formed $\mathrm{CoO}$ in the CO-PROX gas remained in the same state because of the constraint of Pt and low temperature, and exhibited a similar activity to that of the PROX. Therefore, the activity retained a similar $40 \%$ CO conversion, which is different from the performance of leached Pt-Fe catalyst. The next several cycles between COOX and CO-PROX did not cause much difference in activity (Fig. 8(d-f)). In addition, we observed a phenomenon in which leached

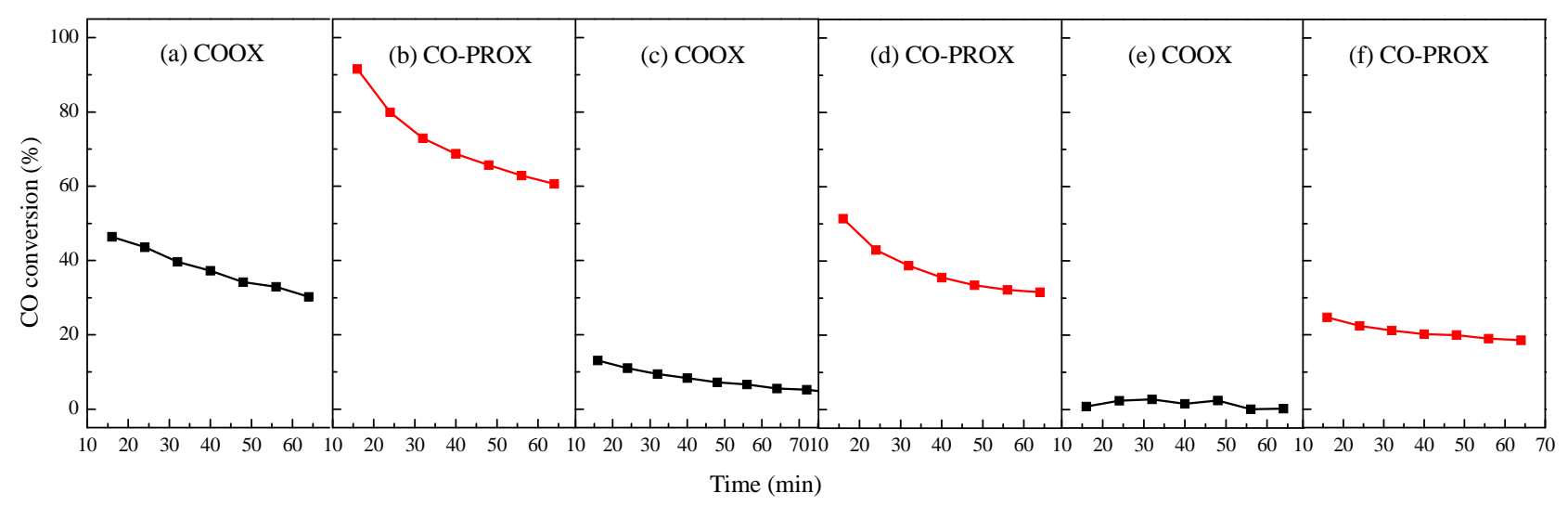

Fig. 7. CO conversion data over leached Pt-Fe/CB oxidized at $250{ }^{\circ} \mathrm{C}$ in various reactive gas atmospheres (COOX and CO-PROX) at $30{ }^{\circ} \mathrm{C}$. 


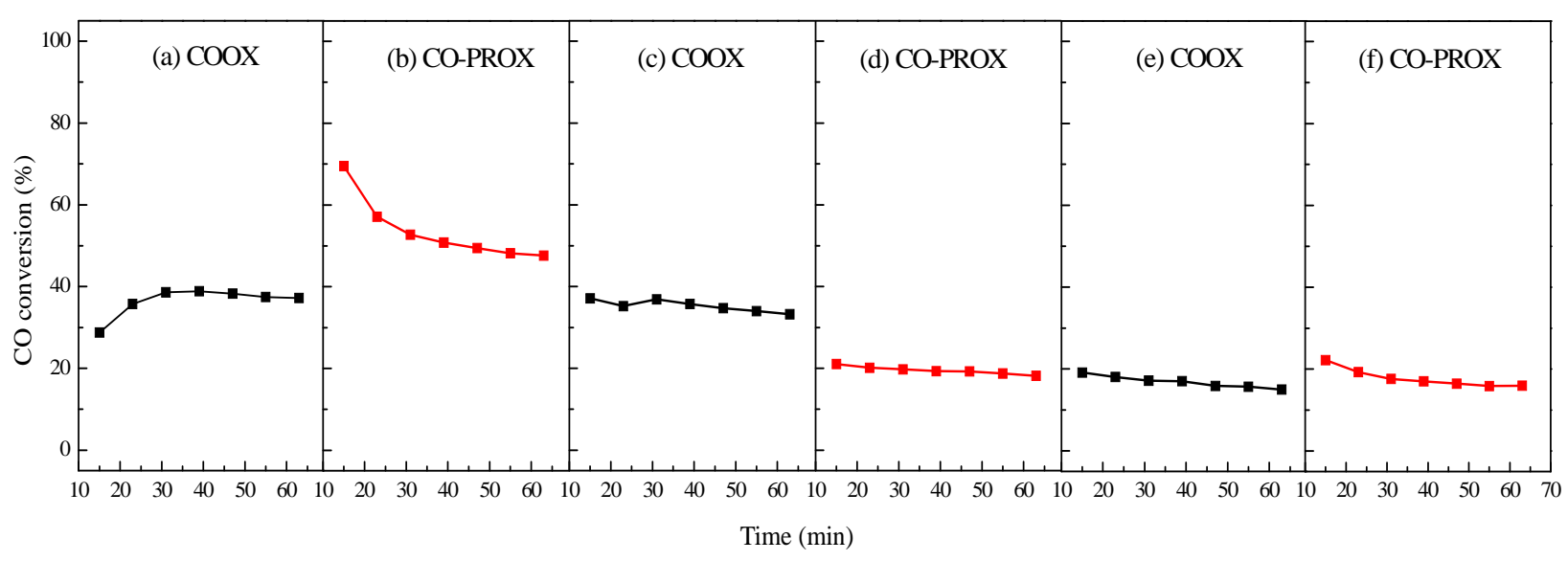

Fig. 8. CO conversion data over leached Pt-Co/CB oxidized at $250^{\circ} \mathrm{C}$ in various reactive gas atmospheres (COOX and CO-PROX) at $30^{\circ} \mathrm{C}$.

Pt-Fe/CB and Pt-Co/CB catalysts exhibit decreased CO conversion with increasing time, regardless of the reaction atmosphere. This may be caused by instability of the skeleton structure of Pt-based nanoparticles after exposure to the acid solution $[46,47]$.

Based on the above results, the structure changes of leached Pt-Fe and Pt-Co nanoparticles can be derived, as shown in Fig. 9. Fully oxidized $\mathrm{Fe}_{2} \mathrm{O}_{3}$ phases exist on the particle surface after leached Pt-Fe catalyst is oxidized at $250{ }^{\circ} \mathrm{C}$, resulting in the low reactivity of the COOX reaction (Fig. 9(a)). When switching to PROX gas, surface $\mathrm{Fe}_{2} \mathrm{O}_{3}$ will be reduced to active $\mathrm{FeO}$ species at RT because of the Pt surface constraining effect and $\mathrm{H}_{2}$-rich gas. The unsaturated $\mathrm{FeO}$ structure at the interfaces shows high ability for $\mathrm{O}_{2}$ activation. A change in reaction environments may lead to kinetic transitions between these two states, and oscillating activities have been observed (Fig. $9(\mathrm{a}, \mathrm{b})$ ). For the leached Pt-Co catalyst, $\mathrm{Co}_{3} \mathrm{O}_{4}$ as the main existing formation combined with a small quantity of $\mathrm{CoO}$ present on the particle surface shows lower reactivity in COOX (Fig. 9(c)). When switching to PROX gas, a similar change may occur with less active $\mathrm{Co}_{3} \mathrm{O}_{4}$ to highly active $\mathrm{CoO}$, which can be explained by hydrogen atoms spilling over from Pt to neighboring $\mathrm{Co}_{3} \mathrm{O}_{4}$, which makes $\mathrm{Co}_{3} \mathrm{O}_{4}$ much easier to be reduced, even at RT. The CoO-on-Pt structures (Fig. 9 (d, e)) formed in the PROX gas would be stable in both reactive conditions at moderate temperatures and show similar performances. CO oxidation occurs according to the bifunctional mechanism, in which a boundary is formed between the $\mathrm{FeO}$ (or $\mathrm{CoO}$ ) and $\mathrm{Pt}$ for $\mathrm{O}_{2}$ activation and nearby $\mathrm{Pt}$ atoms for $\mathrm{CO}$ adsorption.

\section{Conclusions}

Supported inverse oxide/metal catalysts containing $\mathrm{FeO}_{x} / \mathrm{Pt}$ and $\mathrm{CoO}_{x} / \mathrm{Pt}$ were fabricated successfully and applied in $\mathrm{CO}$ oxidation reactions. Acid leaching treatment forms a structure incorporating a Pt-rich shell and an Fe (or Co)-rich bulk. Fully oxidized $\mathrm{Fe}_{2} \mathrm{O}_{3}$ and $\mathrm{Co}_{3} \mathrm{O}_{4}$ exist on the surface of Pt nanoparticles and have lower activity in COOX reactions. The fully oxidized species can be reduced to active $\mathrm{FeO}$ and $\mathrm{CoO}$ species for $\mathrm{O}_{2}$ activation, which exhibit much higher activity for CO-PROX reactions. The structural transformation of Fe oxides can be realized by switching the reactive gases between COOX and CO-PROX reactions, leading to oscillating performance. In contrast, the $\mathrm{CoO}$ surface structure formed in CO-PROX gas is also

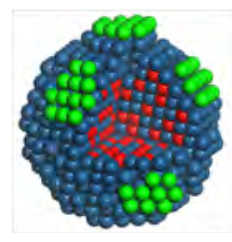

(a)

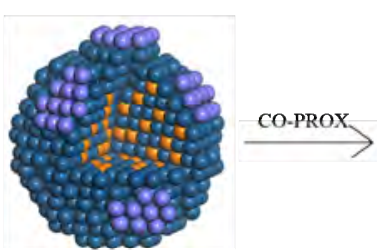

(c)

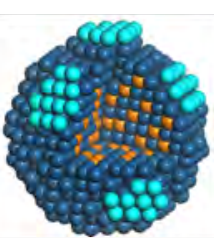

(d)

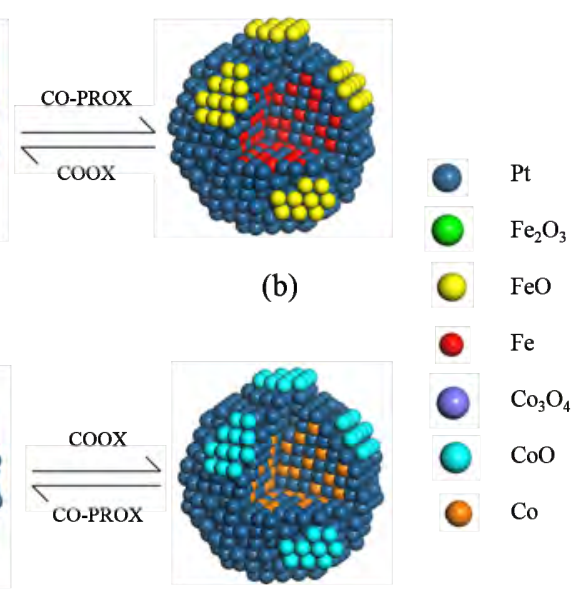

(e)

Fig. 9. Schematic diagrams of the active structures of leached Pt-Fe (a, b) and leached Pt-Co (c, d, e) nanoparticles oxidized at $250{ }^{\circ} \mathrm{C}$ in $\mathrm{COOX}$ and CO-PROX reactions. 


\section{Graphical Abstract}

Chin. J. Catal., 2017, 38: 1261-1269 doi: 10.1016/S1872-2067(17)62838-9

\section{Comparative studies of leached Pt-Fe and Pt-Co catalysts for CO oxidation reactions}

Hong Xu, Ke Ni, Xiaokun Li, Sheng Zhu, Guohong Fan *

Anhui University of Technology

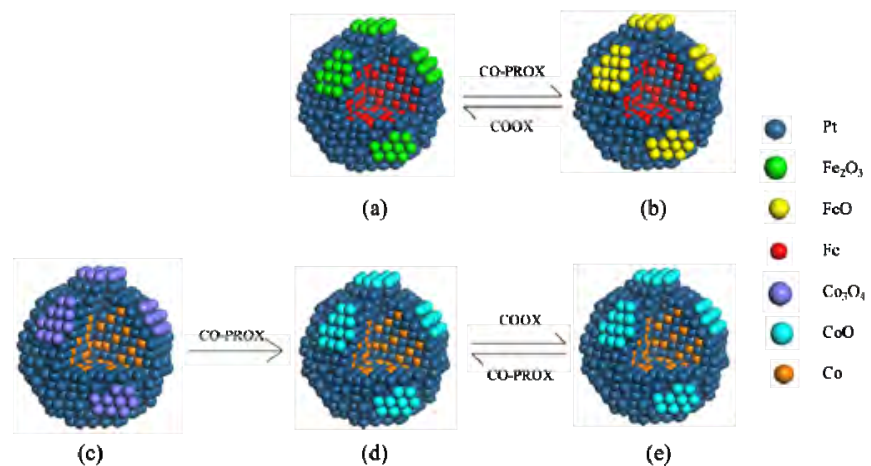

The structure of metal oxides on nanoparticle surfaces can be obtained by oxidizing the leached Pt-Fe and Pt-Co catalysts. The relationship between surface oxides and the catalytic performance for $\mathrm{CO}$ oxidation reactions was studied.

stable when exposed to the COOX atmosphere at RT. As a consequence, the activity of these reactions shows little difference in the $\mathrm{CoO} / \mathrm{Pt}$ structure.

\section{References}

[1] F. Tao, M. E. Grass, Y. W. Zhang, D. R. Butcher, J. R. Renzas, Z. Liu, J. Y. Chung, B. S. Mun, M. Salmeron, G. A. Somorjai, Science, 2008, 322, 932-934.

[2] F. Tao, S. Dag, L. W. Wang, Z. Liu, D. R. Butcher, H. Bluhm, M. Salmeron, G. A. Somorjai, Science, 2010, 327, 850-853.

[3] Z. W. Zhu, F. F. Tao, F. Zheng, R. Chang, Y. M. Li, L. Heinke, Z. Liu, M. Salmeron, G. A. Somorjai, Nano Lett, 2012, 12, 1491-1497.

[4] F. Yang, J. Graciani, J. Evans, P. Liu, J. Hrbek, J. F. Sanz, J. A. Rodriguez, J. Am. Chem. Soc., 2011, 133, 3444-3451.

[5] T. Yan, D. W. Redman, W. Y. Yu, D. W. Flaherty, J. A. Rodriguez, C. B. Mullins, J. Catal., 2012, 294, 216-222.

[6] S. D. Senanayake, D. Stacchiola, J. A. Rodriguez, Acc. Chem. Res., 2013, 46, 1702-1711.

[7] J. A. Rodriguez, S. Ma, P. Liu, J. Hrbek, J. Evans, M. Perez, Science, 2007, 318, 1757-1760.

[8] J. A. Rodriguez, J. Graciani, J. Evans, J. B. Park, F. Yang, D. Stacchiola, S. D. Senanayake, S. G. Ma, M. Perez, P. Liu, J. Fdez Sanz, J. Hrbek, Angew. Chem. Int. Ed., 2009, 48, 8047-8050.

[9] J. Graciani, K. Mudiyanselage, F. Xu, A. E. Baber, J. Evans, S. D. Senanayake, D. J. Stacchiola, P. Liu, J. Hrbek, J. F. Sanz, J. A. Rodriguez, Science, 2014, 345, 546-550.

[10] S. D. Senanayake, P. J. Ramírez, I. Waluyo, S. Kundu, K. Mudiyanselage, Z. Y. Liu, Z. Liu, S. Axnanda, D. J. Stacchiola, J. Evans, J. A. Rodriguez, J. Phys. Chem. C, 2016, 120, 1778-1784.

[11] J. A. Rodríguez, J. Hrbek, Surf. Sci., 2010, 604, 241-244.

[12] L. Yu, Y. Liu, F. Yang, J. Evans, J. A. Rodriguez, P. Liu, J. Phys. Chem. C, 2015, 119, 16614-16622.

[13] Q. Fu, F. Yang, X. H. Bao, Acc. Chem. Res., 2013, 46, 1692-1701.

[14] Q. Fu, W. X. Li, Y. Yao, H. Liu, H. Y. Su, D. Ma, X. K. Gu, L. Chen, Z. Wang, H. Zhang, B. Wang, X. Bao, Science, 2010, 328, 1141-1144.

[15] R. T. Mu, Q. Fu, H. Xu, H. Zhang, Y. Y. Huang, Z. Jiang, S. Zhang, D. L. Tan, X. H. Bao, J. Am. Chem. Soc., 2011, 133, 1978-1986.
[16] H. Xu, Q. Fu, Y. X. Yao, X. H. Bao, Energy Environ. Sci., 2012, 5, 6313-6320.

[17] H. Xu, Q. Fu, X. G. Guo, X. H. Bao, ChemCatChem, 2012, 4 , 1645-1652.

[18] S. Axnanda, Z. W. Zhu, W. P. Zhou, B. H. Mao, R. Chang, S. Rani, E. Crumlin, G. Somorjai, Z. Liu, J. Phys. Chem. C, 2014, 118, 1935-1943.

[19] W. P. Zhou, S. Axnanda, M. G. White, R. R. Adzic, J. Hrbek, J. Phys. Chem. C, 2011, 115, 16467-16473.

[20] G. Krenn, J. Schoiswohl, S. Surnev, F. P. Netzer, R. Schennach, Top. Catal., 2007, 46, 231-238.

[21] S. Surnev, M. Sock, G. Kresse, J. N. Andersen, M. G. Ramsey, F. P. Netzer, J. Phys. Chem. B, 2003, 107, 4777-4785.

[22] Y. Suchorski, R. Wrobel, S. Becker, H. Weiss, J. Phys. Chem. C, 2008, 112, 20012-20017.

[23] S. Altieri, L. H. Tjeng, G. A. Sawatzky, Phys. Rev. B, 2000, 61, 16948-16955.

[24] S. Altieri, L. H. Tjeng, G. A. Sawatzky, Thin Solid Films, 2001, 400 9-15.

[25] J. A. Rodriguez, P. Liu, J. Graciani, S. D. Senanayake, D. C. Grinter, D. Stacchiola, J. Hrbek, J. Fernandez-Sanz, J. Phys. Chem. Lett., 2016, 7, 2627-2639.

[26] H. Xu, Q. Fu, X. H. Bao, Chin. J. Catal., 2013, 34, 2029-2035.

[27] J. R. Kitchin, N. A. Khan, M. A. Barteau, J. G. Chen, B. Yakshinskiy, T. E. Madey, Surf. Sci., 2003, 544, 295-308.

[28] N. A. Khan, L. E. Murillo, J. G. Chen, J. Phys. Chem. B, 2004, 108, 15748-15754.

[29] J. Knudsen, A. U. Nilekar, R. T. Vang, J. Schnadt, E. L. Kunkes, J. A. Dumesic, M. Mavrikakis, F. Besenbacher, J. Am. Chem. Soc., 2007, 129, 6485-6490.

[30] T. Wadayama, H. Osano, T. Maeyama, H. Yoshida, K. Murakami, N. Todoroki, S. Oda, J. Phys. Chem. C, 2008, 112, 8944-8950.

[31] A. V. Ruban, H. L. Skriver, J. K. Nörskov, Phys. Rev. B, 1999, 59, 15990-16000.

[32] R. T. Mu, Q. Fu, H. Y. Liu, D. L. Tan, R. S. Zhai, X. H. Bao, Appl. Surf. Sci., 2009, 255, 7296-7301.

[33] P. Strasser, S. Koh, T. Anniyev, J. Greeley, K. More, C. F. Yu, Z. C. Liu, S. Kaya, D. Nordlund, H. Ogasawara, M. F. Toney, A. Nilsson, Nat. 
Chem., 2010, 2, 454-460.

[34] P. C. J. Graat, M. A. J. Somers, Appl. Surf. Sci, 1996, 100-101, 36-40.

[35] T. Yamashita, P. Hayes, Appl. Surf. Sci., 2008, 254, 2441-2449.

[36] V. Papaefthimiou, T. Dintzer, V. Dupuis, A. Tamion, F. Tournus, D. Teschner, M. Hävecker, A. Knop-Gericke, R. Schlögl, S. Zafeiratos, J. Phys. Chem. Lett., 2011, 2, 900-904.

[37] S. R. Zhang, J. J. Shan, Y. Zhu, A. I. Frenkel, A. Patlolla, W. X. Huang, S. J. Yoon, L. Wang, H. Yoshida, S. Takeda, F. F. Tao, J. Am. Chem. Soc., 2013, 135, 8283-8293.

[38] C. Wang, B. D. Li, H. Q. Lin, Y. Z. Yuan, J. Power Sources, 2012, 202, 200-208.

[39] S. Alayoglu, G. A. Somorjai, Catal. Lett., 2015, 145, 249-271.

[40] B. Yang, G. Khadra, J. Tuaillon-Combes, E. C. Tyo, M. J. Pellin, B. Reinhart, S. Seifert, X. Q. Chen, V. Dupuis, S. Vajda, J. Phys. Chem. C, 2016, 120, 21496-21504.
[41] Q. Fu, Y. X. Yao, X. G. Guo, M. M. Wei, Y. X. Ning, H. Y. Liu, F. Yang, Z. Liu, X. H. Bao, Phys. Chem. Chem. Phys., 2013, 15, 14708-14714.

[42] W. C. Conner, J. L. Falconer, Chem. Rev., 1995, 95, 759-788.

[43] R. T. Mu, Q. Fu, X. G. Guo, X. J. Xu, D. L. Tan, X. H. Bao, Sci. China Chem., 2015, 58, 162-168.

[44] J. Yin, J. H. Wang, T. Zhang, X. D. Wang, Catal. Lett., 2008, 125, 76-82.

[45] F. Zheng, S. Alayoglu, J. H. Guo, V. Pushkarev, Y. M. Li, P. A. Glans, J. L. Chen, G. Somorjai, Nano Lett., 2011, 11, 847-853.

[46] C. Wang, M. F. Chi, D. G. Li, D. Strmcnik, D. van der Vliet, G. F. Wang, V. Komanicky, K. C. Chang, A. P. Paulikas, D. Tripkovic, J. Pearson, K. L. More, N. M. Markovic, V. R. Stamenkovic, J. Am. Chem. Soc., 2011, 133, 14396-14403.

[47] V. R. Stamenkovic, B. S. Mun, K. J. J. Mayrhofer, P. N. Ross, N. M. Markovic, J. Am. Chem. Soc., 2006, 128, 8813-8819.

\title{
酸洗Pt-Fe和Pt-Co催化剂在CO氧化反应中的对比研究
}

\author{
徐红, 倪 可, 李小昆, 朱胜, 范果红 \\ 安徽工业大学化学与化工学院, 安徽马鞍山243002
}

摘要: 负载型纳米催化剂表面结构与其催化性能之间关系的研究一直受到广泛关注. 由于其结构复杂使得人们在研究催 化剂构效关系时遇到了很多困难. 近年来, 大量研究发现反转催化剂在众多反应中表现出优越的催化性能. 反转催化剂是 将过渡金属氧化物负载于其它金属表面. 和传统金属/氧化物催化剂相比, 反转催化剂更能突出氧化物在催化反应中的重 要作用. 众多研究表明, 在氧化物-金属界面处存在特殊的作用, 这种作用可以改变氧化物的电子特性和化学性质, 进而产 生较高的催化性能. 傅强等人创建了金属氧化物负载于Pt表面的反转催化体系, 其表现出了高的低温CO氧化反应性能. 在 氧化物和Pt之间的界面限域效应可以稳定氧化物中配位不饱和的金属阳离子. 这种配位不饱和的氧化物提供了活化 $\mathrm{O}_{2}$ 的 活性位. 目前, 反转催化剂的研究主要集中在单晶模型体系中, 在负载型催化剂中的研究还较少. 我们以炭黑(CB)为载体, 将还原后的Pt-Fe和Pt-Co催化剂经过酸洗制备了一种表面富Pt核为合金的结构. 考察了酸洗后的Pt-Fe和Pt-Co催化剂经过 不同温度氧化后的结构变化, 并讨论了其结构与CO完全氧化反应(COOX)和CO选择氧化反应(CO-PROX)性能的关系.

X射线粉末衍射(XRD), 电感耦合等离子体发射光谱(ICP), 透射电镜(TEM)和X射线光电子能谱(XPS)表征结果表明, 还 原后的Pt基催化剂经过酸洗可以选择性去除纳米粒子表面的 $3 d$ 过渡金属, 形成表面富Pt体相为合金的结构. 将酸洗后的 $\mathrm{Pt}-\mathrm{Fe}$ 和Pt-Co催化剂在不同温度下空气中氧化, 发现近表层的 $\mathrm{Fe}(\mathrm{Co})$ 会扩散到粒子表面上, 形成过度氧化的 $\mathrm{Fe}_{2} \mathrm{O}_{3}\left(\mathrm{Co}_{3} \mathrm{O}_{4}\right)$ 表 面结构. 氧化后的催化剂在COOX和CO-PROX反应中表现出截然不同的催化性能. 酸洗后的Pt-Fe(Pt-Co)催化剂经过不同 温度氧化后在COOX反应中活性都较差, 室温下的CO转化率只有不到 $30 \%, \mathrm{CO}$ 完全转化的温度超过 $100{ }^{\circ} \mathrm{C}$, 相当于纯Pt催 化剂的活性. 这说明 $\mathrm{Pt}$ 表面过度氧化的 $\mathrm{Fe}_{2} \mathrm{O}_{3}\left(\mathrm{Co}_{3} \mathrm{O}_{4}\right)$ 对 $\mathrm{CO}$ 氧化反应的促进作用不明显. 而氧化后的催化剂在CO-PROX反 应中表现出较高的活性, $250{ }^{\circ} \mathrm{C}$ (或350 ${ }^{\circ} \mathrm{C}$ )氧化后的酸洗Pt-Fe催化剂室温下的CO转化率接近 $100 \%, 250{ }^{\circ} \mathrm{C}\left(\right.$ 或 $350{ }^{\circ} \mathrm{C}$ )氧化 后的酸洗Pt-Co催化剂室温下的CO转化率也达到了 70\%. 结合表征和反应结果, 我们认为氧化处理形成的表面过度氧化的 金属氧化物 $\left(\mathrm{Fe}_{2} \mathrm{O}_{3}, \mathrm{Co}_{3} \mathrm{O}_{4}\right)$ 在COOX的催化性能较差. 通入CO-PROX反应气后, 气氛中大量 $\mathrm{H}_{2}$ 的存在和 $\mathrm{Pt}$ 表面的氢溢流效 应可以使得表面 $\mathrm{Fe}_{2} \mathrm{O}_{3}, \mathrm{Co}_{3} \mathrm{O}_{4}$ 在室温下被还原成配位不饱和的 $\mathrm{FeO}, \mathrm{CoO}$. 这种配位不饱和的氧化物在表面Pt的限域作用和 大量 $\mathrm{H}_{2}$ 气氛下比较稳定, 并且具有较强的活化解离 $\mathrm{O}_{2}$ 的能力, 进而提高了CO-PROX反应的活性.

为了进一步证实催化剂表面氧化物与其催化性能的关系, 我们在室温下进行了两种反应气的循环实验测试. 测试结 果表明, 对于氧化后的酸洗Pt-Fe催化剂, $\mathrm{COOX}$ 反应中的表面 $\mathrm{Fe}_{2} \mathrm{O}_{3}$ 和CO-PROX反应中的表面FeO可以通过变换反应气氛 实现两种氧化物的相互转变, 并表现出完全不同的催化性能. 对于氧化后的酸洗Pt-Co催化剂, CO-PROX反应中形成的 $\mathrm{CoO}$ 表面结构在COOX反应中也比较稳定, 在两种反应气中表现出相似的催化性能.

关键词: 铂-铁; 铂-钴; 酸洗; $\mathrm{CO}$ 氧化; 表面氧化物

收稿日期: 2017-04-10. 接受日期: 2017-04-12. 出版日期: 2017-07-05.

*通讯联系人. 电话: (0555)2311807; 电子信箱: ghfan8@ahut.edu.cn

基金来源：国家自然科学基金(21403004, 21403003).

本文的英文电子版由Elsevier出版社在ScienceDirect上出版(http://www.sciencedirect.com/science/journal/18722067). 